Revista de Derecho Yachaq N. 8 - Diciembredel 2017

Centro de Investigación de los Estudiantes de Derecho (CIED)

Universidad Nacional San Antonio Abad del Cusco

ISSN: 2707-1197 (en línea)

ISSN: 1817-597X (impresa)

Fecha de recepción: 20/08/2017

Fecha de aceptación: 05/09/2017

[pp. 78-90]

\title{
ALGUNAS CONSIDERACIONES GENERALES SOBRE EL NUEVO CÓDIGO CIVIL Y COMERCIAL ARGENTINO Y EN ESPECIAL SOBRE EL DERECHO DE OBLIGACIONES*
}

\author{
SOME GENERAL CONSIDERATIONS ON THE NEW ARGENTINE CIVIL AND \\ COMMERCIAL CODE AND ESPECIALLY ON THE LAW OF OBLIGATIONS
}

\begin{abstract}
Mario Castillo Freyre**
RESUMEN: En el presente artículo, se reflexiona sobre la situación de la reforma de los códigos civiles, con énfasis en el contexto argentino, analizando la importancia de las normas codificadas y la relación intrínseca que tienen con la praxis jurídica para reafirmar su eficacia en comparación a códigos anteriores, dirigidas por expertos del derecho, quienes tienen la tarea de alejarse de toda postura doctrinal o pensamiento político que afecte el diseño de tales reformas. Asi mismo, desarrolla un análisis crítico respecto de algunas normas abarcadas en el Código Civil y Comercial argentino, haciendo énfasis a la contradictoria definición que estos cuerpos normativos realizan sobre las instituciones jurídicas de las obligaciones y la obligación de dar dinero, justificando la contradicción que surge al incluirlas en estos códigos de carácter público, siendo que se hace uso de eufemismos y conceptos que llegan a generar diferentes interpretaciones, en su mayoría contradictoria Finalmente, advierte el riesgo que conllevan las cláusulas penales y su mutabilidad al tratarse de indemnizar o suplir con multas aquellos daños y perjuicios que podrían ser desproporcionales al pago de una penalidad.
\end{abstract}

PALABRAS CLAVE: Reforma - Partidarios - Detractores - Obligaciones - Penalidad

ABSTRACT: The following article reflects the situation of the reform of civil codes, with emphasis on the Argentine context, analyzing the importance of codified norms and the intrinsic relationship they have with legal practice to reaffirm their effectiveness in comparison to previous codes, directed by legal experts, who have the task of moving away from any doctrinal position or political thought that affects the design of such reforms. Likewise, it develops a critical analysis regarding some norms covered in the Argentine Civil and Commercial Code, emphasizing the contradictory definition that these normative bodies carry out on the legal institutions of the obligations and the obligation to give money, justifying the contradiction that arises by

\footnotetext{
* Ponencia pronunciada el viernes 15 de mayo de 2015, en la ciudad de San Juan, República Argentina, en el marco de la Quinta Jornada Sanjuanina de Derecho Civil y del Primer Congreso Internacional de Derecho Privado.

** Abogado en ejercicio; socio del Estudio que lleva su nombre. Magíster y Doctor en Derecho por la Pontificia Universidad Católica del Perú, casa de estudios en la que es profesor principal. Director de las colecciones Biblioteca de Arbitraje y Biblioteca de Derecho de su Estudio. Director de la Revista Peruana de Derecho.estudio@castillofreyre.com
} 
including them in these codes of public nature, using euphemisms and concepts that come to generate different interpretations, mostly contradictory. Finally, it warns of the risk that criminal clauses carry and their mutability when it comes to compensate or supplement with fines those damages that could be disproportionate to the payment of a penalty.

KEY WORDS: Reform - Supporters - Detractors - Obligations - Penalty 


\section{Algunas Consideraciones Generales Sobre El Nuevo Código Civil y Comercial ARgentino y En ESPECIAL SOBRe El Derecho De Obligaciones*}

\author{
Mario Castillo Freyre \\ Abogado en ejercicio; socio \\ del Estudio que lleva su \\ nombre. Magister y Doctor \\ en Derecho por la Pontificia \\ Universidad Católica del Perú, \\ casa de estudios en la que es \\ profesor principal. Director \\ de las colecciones Biblioteca \\ de Arbitraje y Biblioteca de \\ Derecho de su Estudio. Director \\ de la Revista Peruana de \\ Derecho.
}

\begin{abstract}
SUMARIO: 1.- Introducción, 2. La reforma de los códigos y sus problemas, 3.- Algunos comentarios sobre el nuevo Código argentino y el Derecho de Obligaciones, 3.1.- El concepto de obligación (artículo 724 del nuevo Código argentino), 3.2.- Obligaciones de dar dinero (artículo 765 del nuevo Código argentino), 3.3-. La cláusula penal (artículos 790 y siguientes del nuevo Código argentino), 4.Comentarios finales
\end{abstract}

\section{1.- Introducción}

$\mathrm{E}$ evento, para asistir a esta hermosa ciudad de San Juan, que tengo el placer de visitar por primera vez. En especial, mi agradecimiento al profesor Pascual Alferillo, quien tuvo la gentileza de convocarme para participar en estas clásicas Jornadas.

No cabe duda de que el Derecho argentino vive una etapa muy especial, en la medida de que, dentro de poco tiempo, entrará en vigencia un nuevo Código Civil.

En lo personal, viví una etapa similar cuando recién comenzaba mis estudios de Derecho en el Perú, dado que, precisamente, los inicié en agosto de 1984, cuando todavía regía el Código Civil de 1936, pero acababa de ser promulgado, el 24 de julio, el Código que empezaría a tener vigencia el 14 de noviembre de ese mismo año.

Recuerdo cómo, durante toda mi carrera, fue inevitable que nuestros profesores, muchos de los cuales habían sido autores de ese nuevo Código, compararan minuciosamente en sus clases, el contenido del cuerpo normativo de 1936, con el de 1984.

\footnotetext{
* Ponencia pronunciada el viernes 15 de mayo de 2015, en la ciudad de San Juan, República Argentina, en el marco de la Quinta Jornada Sanjuanina de Derecho Civil y del Primer Congreso Internacional de Derecho Privado.
} 
Una reforma legislativa tan importante como aquella que consiste en cambiar de Código Civil, plantea no sólo debates, sino también cuestiones ineludibles que resulta necesario mencionar y que, sin duda, van a reproducirse en, prácticamente, todos los países en donde se dé un proceso de esta naturaleza.

\section{2.- La reforma de los códigos y sus problemas}

Antes de proceder a abordar algunas ideas sobre el Derecho de Obligaciones en este nuevo Código, voy a permitirme tratar un tema de fondo, que me parece indispensable para situar en contexto las opiniones que se vierten acerca del nuevo Código y del Código que se está derogando.

2.1. Todo nuevo Código tratará de llenar los vacíos que la doctrina y la jurisprudencia detectaron en el anterior.

Ello, pues la reforma de un artículo o de una materia abordada en un Código Civil, carecería de objeto si no se hubiese producido, con el transcurso de los años, un proceso en el que se hubieran detectado falencias en la norma.

Dicho esto, lo que corresponderá saber es si el nuevo precepto contiene aspectos que ha resultado necesario o indispensable reformar, o si, por el contrario, sólo es fruto de tentaciones académicas.

En otras palabras, la pregunta de fondo será si, en caso no se hubiese modificado la norma original, el Derecho del país en cuestión, hubiese seguido interpretando lo mismo en torno al problema bajo tratamiento.

Así, siempre estará presente la discusión —inacabable, por cierto—, entre quienes sostengan la imperiosa necesidad de la reforma producida, y quienes estimen lo contrario.

En lo personal, siempre he sido muy cauto en torno a introducir en los Códigos, todo aquello que la doctrina y la jurisprudencia han dado como contenido de vida a una norma legal precedente.

Los profesores de Derecho debemos tener mucho cuidado al transitar ese difícil camino que implica el saber cuándo resulta necesario modificar una norma o una institución en un Código Civil, y cuándo no lo es.

En otras palabras, si la doctrina y la jurisprudencia han dejado aclarado el sentido de un problema, puede que ese «problema» ya no exista en la vida real, habida cuenta de que el Derecho no sólo es la norma legal, sino todas las fuentes que lo integran.

2.2. De lo expuesto, resulta inevitable que siempre haya partidarios y detractores de un nuevo Código Civil. Es claro que todo proceso de reforma va a acarrear como consecuencia, el que parte del medio jurídico y social apoye la reforma, y otra parte la rechace. 
Tomar partido a priori por alguno de estos grupos de pensamiento no es lo que corresponde a un extranjero, como es mi caso, quien, sin duda, tiene buenos amigos, tanto en uno como en otro; además de que no soy un experto en el Derecho de este país.

Pero, lo que sí me corresponde es pronunciarme sobre algunas cuestiones que, al igual que las desarrolladas en el punto anterior, considero de validez casi universal.

Ellas pasan por el hecho de que no necesariamente el apoyar un nuevo Código Civil implica estar a la vanguardia del Derecho; lo que acarrea como correlato que tampoco resultará a priori cierto, que quienes se opongan a esta modificación legislativa tengan una visión retrógrada del mismo.

No existe un terreno más opinable que aquél referido a cómo debe legislarse una determinada figura o institución; de modo que será totalmente lícito estar a favor de la modificación integral de un Código Civil, como preferir que ella no hubiera ocurrido.

Por lo demás, encontrándonos ante un objeto legislativo tan voluminoso, en la mayoría de casos no se tratará de adhesiones completas en uno u otro sentido.

Es claro que ni los propios autores de un nuevo Código Civil estarán de acuerdo sobre el sentido de todas sus normas, habida cuenta de que legislar de manera colectiva o en comisiones de trabajo, implica una permanente transacción, lo que es inevitable entre todo grupo humano que quiere llevar adelante una determinada empresa.

2.3. Cuando el medio jurídico ha estado dividido en torno a la idea de cambiar o no de Código Civil, y el proceso ha sido duro, a la vez que difícil, no cabe duda de que el mismo siempre dejará heridas entre quienes han participado en la batalla.

Pero, en estos casos, tampoco debe pensarse que la guerra se ha ganado o perdido cuando se aprueba un nuevo Código, pues allí empiezan otras batallas — tal vez tan o más difíciles que las anteriores-, las mismas que consistirán en demostrar las bondades del Código con respecto a su predecesor, a la par que probar, con el paso del tiempo y de la práctica jurídica, que las nuevas normas son, no sólo en la letra, sino en la vida real, superiores y más beneficiosas que las del Código precedente.

Este proceso, que se inicia con la promulgación legislativa de todo nuevo Código Civil, determinará que la doctrina y la jurisprudencia vayan poniendo en su sitio los nuevos preceptos y aquilatando su verdadero valor jurídico.

Ello significa que el tiempo, finalmente, o dará la razón a quienes propugnaron y elaboraron el nuevo cuerpo normativo, o se la dará a sus adversarios, o, simplemente, que la historia reconocerá que la razón estaba compartida, lo que usualmente ocurre en la vida real. 
2.4. El riesgo de las doctrinas hechas ley.

Siendo el Derecho fuente de permanente debate en cuanto al alcance de los conceptos de las diversas figuras e instituciones que lo componen, y siendo nosotros los civilistas expertos en discutir y debatir tales conceptos, a la par que en asumir los propios y rebatir los ajenos, hay un punto sobre el que resulta necesario formular una advertencia; y es el relativo a introducir en los nuevos Códigos conceptos o definiciones que, supuestamente, zanjen el sentido o discusión de las instituciones que se abordan.

Por poner un ejemplo en abstracto, si sobre un tema ha existido siempre una discusión acerca de la conveniencia de interpretar una norma en el sentido de que ella recogía la teoría subjetiva o la teoría objetiva, y tanto la doctrina como la jurisprudencia, se encontraban divididas sobre el particular, no necesariamente será sano que un nuevo Código Civil opte por uno de los dos criterios, pues al fin y al cabo, se trataría de una toma de partido, probablemente, inútil, en la medida de que si esa discusión era tan fuerte en la doctrina y jurisprudencia, el legislador no tendrá suficiente autoridad jurídica como para zanjarla de un plumazo.

Por lo demás, si se pensara que con una decisión de esta naturaleza el problema habría sido superado, se incurriría en una profunda equivocación, pues la nueva norma legal no disipará la divergencia del medio jurídico, sino, probablemente, la acentúe y encrespe.

Así, no se habrá solucionado nada, sino se habrán empeorado las cosas.

\subsection{El Derecho Civil y la Política}

Lo ideal es que el debate sobre las modificaciones normativas en el campo civil, no esté contaminado por la discusión político-partidaria.

Cuando hablamos de la modificación legislativa integral en materia civil, no hay duda de que estamos ante un tema de la mayor importancia para la población, y ella debe producirse de cara a la sociedad en su conjunto, pero fundamentalmente, ser objeto de un debate técnico, académico y estrictamente ceñido a los ámbitos de la profesión.

Me temo que cuando las modificaciones de los Códigos se contaminan con la discusión política, poco o nada bueno aporta esta situación al ámbito civil.

No olvidemos que no estamos ante el debate de una nueva Constitución, sino ante el de un nuevo Código Civil.

Además, si sumamos las pasiones políticas a las pasiones jurídicas, es fácil advertir que nos encontraremos ante una combinación altamente explosiva. Ello ocurrió en mi país, cuando la más reciente dictadura emprendió la frustrada tarea de una reforma integral del Código. 
Digo esto, en razón a que los Códigos Civiles deben tener una firme vocación de permanencia en el tiempo, lo que brinda estabilidad y progreso a las sociedades que están destinadas a regir.

2.6. Por último, los debates y las críticas que ineludiblemente surgirán en todo proceso de modificación legislativa, deben estar dirigidos al combate de las posiciones jurídicas y no al de sus autores.

En el Derecho Civil y en la vida profesional y académica debe prevalecer la mayor consideración por el otro, por más de que sus posiciones las estimemos profundamente equivocadas.

En casos como éstos, lo que uno debe pretender es vencer la posición del otro; no destruir al otro.

Quisiera que me disculpen por haber destinado la primera parte de mi ponencia al desarrollo de estas ideas generales sobre la reforma de los Códigos Civiles, las mismas que he trabajado y desarrollado a lo largo de los años, en razón de la experiencia vivida en mi país, cuyo Código, de 1984, no obstante su juventud, ha intentado ser reformado — sin éxito- de manera integral en múltiples ocasiones, prácticamente cada cinco o diez años.

Siempre me opuse frontalmente a todos los intentos y comisiones reformadoras de ese Código, situación que, confieso, me acarreó la pérdida de algunos buenos amigos en el medio académico.

Pero, en estas materias, lo más importante es exponer aquello en lo que uno cree, siendo consciente de que nadie es dueño de la verdad absoluta.

\section{3.- Algunos comentarios sobre el nuevo Código argentino y el Derecho de Obligaciones}

La segunda parte de mi ponencia se va a centrar en el análisis de algunos preceptos relacionados al Derecho de Obligaciones que ha regulado el nuevo Código Civil y Comercial argentino. Me centraré en la referencia de algunas de dichas normas, pues no constituye objeto de esta ponencia el análisis integral de esta parte de la legislación de un país distinto al mío, lo que, por lo demás, escaparía razonablemente a las pretensiones de esta intervención.

\section{1.- El concepto de obligación (artículo 724 del nuevo Código argentino)}

Como sabemos, las obligaciones constituyen una de las más importantes partes del Derecho Privado, pues la vida social depende de ellas.

Como acertadamente sostiene el profesor Ordoqui Castilla, ${ }^{1}$ el Derecho de las Obligaciones ha cobrado particular trascendencia en el mundo moderno, pues sobre sus fundamentos jurídicos se apoyan las instituciones económicas internacionales en mayor nivel por su importancia y participación en el desarrollo económico y cultural de América y del mundo.

1 Cfr. ORDOQUi CASTILlA, Gustavo. Lecciones de Derecho de las Obligaciones. Montevideo: Ediciones «del Foro», 1998, tomo I, p. 23. 
Tal trascendencia en el mundo moderno, conduce — a mi criterio - a la necesidad de que los Códigos definan cada vez menos figuras sobre las que no se requiere una definición específica o — peor aún— sobre las que hay infinidad de conceptos.

Debemos recordar que Vélez Sarsfield, en la nota a su artículo 495, explicitó las razones por las que consideraba impropio o extraño a un Código de leyes la formulación de definiciones: lo estimó ajeno a las atribuciones del legislador, pero sí «del dominio del gramático y del literato en el lenguaje ordinario y atribución del profesor cuando la expresión es técnica».

Digo esto y, al mismo tiempo, me refiero concretamente al concepto de obligación que plantea el nuevo Código a través de su artículo 724, según el cual:

\section{Artículo 724.- Definición}

La obligación es una relación jurídica en virtud de la cual el acreedor tiene el derecho a exigir del deudor una prestación destinada a satisfacer un interés lícito y, ante el incumplimiento, a obtener forzadamente la satisfacción de dicho interés.

Como se puede apreciar, la definición recogida en el citado numeral pone de manifiesto los rasgos más relevantes de la figura y remarca, además, la estructura institucional de la obligación, en la que aparecen el débito y la responsabilidad como tramos de una misma relación obligatoria. Es más, muchos profesores de Derecho, entre ellos quien hace uso de la palabra, podríamos suscribir el concepto contenido en el artículo 724.

Sin embargo, lo aparentemente útil de dicha definición es que intenta ingresar — de modo implícito - al debate en torno al carácter de las denominadas obligaciones naturales, categoría de obligaciones que carecen del rasgo de exigibilidad. Y ello es así, ya que con la frase «derecho a exigir» se estaría estipulando que cuando no existe exigibilidad, nos hallaríamos en presencia de un típico caso de obligación natural.

Sin perjuicio de lo expuesto, debemos recordar que, tanto la doctrina como la jurisprudencia argentinas, ya se han encargado de precisar conceptos en torno a este asunto. Así, la referencia a la exigibilidad que hace la norma del nuevo Código, con el término «exigible», resulta reiterativa e innecesaria, ya que ella es presupuesto de toda obligación. En tal sentido, en lo que se refiere a este aspecto, dicho extremo de la definición legal, resulta innecesario.

Otro tema que creo podría ser reconsiderado en relación al contenido del artículo 724 del Código Civil, es el extremo en el que señala que ante un incumplimiento se podrá forzar a la parte que no cumplió a la satisfacción de dicho interés.

Como sabemos, esta afirmación no necesariamente constituye el único camino ante un incumplimiento, y es que también podría pensarse en la posibilidad (por lo demás válida y completamente lógica en términos prácticos y jurídicos) de permitir que se deje sin efecto la obligación, con el consecuente pago de la indemnización por los daños 
y perjuicios que tal incumplimiento hubiera causado, si fuese el caso; lo cual, además, no constituye la satisfacción del interés (que era la prestación incumplida), sino más bien la única alternativa que el acreedor ahora poseería.

Por otra parte, es claro que no siempre se podrá obligar a una persona a cumplir con la obligación. Ello, en muchos casos, colisionaría con la libertad del ser humano y con los límites que — desde ya hace mucho - impone el Derecho Civil al cumplimiento forzoso de las obligaciones. Tampoco el acreedor conservará necesariamente el interés en un cumplimiento en especie de la obligación.

Aspecto que merece comentario aparte, es el referido al uso en singular que se realiza de los términos «acreedor» y «deudor» y es que con ello se está dejando de lado la figura — muy común, por cierto— de la obligación con pluralidad de sujetos. Lo mismo ocurre con el término «prestación», ya que con esa referencia se deja de lado a las obligaciones de objeto plural, en que hay que ejecutar más de una prestación, y específicamente me refiero a las obligaciones conjuntivas. Así las cosas, en este sentido, la definición que otorga el nuevo Código al término «obligación», no sólo es imprecisa sino incompleta.

Debemos poner énfasis en el hecho de que toda definición siempre regulará aspectos que, en algunas ocasiones, podrían considerarse obvios y, por ende, innecesarios. A contrario, toda definición siempre dejará de lado aspectos muy importantes, como los que nos hemos permitido señalar.

Además, debe tenerse en cuenta que una definición implica un corte en determinado tiempo, espacio y lugar; es decir, es como una fotografía que se toma a una realidad específica. En ese sentido, si un Código Civil contiene definiciones, su vocación de permanencia (que de por sí le debería ser inherente, ya que nadie promulga un Código pensando en derogarlo luego de corto tiempo) se desvirtuaría. Es como si el propio autor de una obra la condenara a una muerte prematura antes de nacer.

Por eso es que siempre he creído que la tarea de definir debe ser dejaba a los profesores de Derecho, en los libros que escriban.

Dentro de tal orden de ideas, me parece que hubiera podido prescindirse del contenido del artículo 724 del nuevo Código.

\section{2.- Obligaciones de dar dinero (artículo 765 del nuevo Código argentino)}

Voy a leer el artículo 765 del Código:

Artículo 765.- Concepto

La obligación es de dar dinero si el deudor debe cierta cantidad de moneda, determinada o determinable, al momento de constitución de la obligación. Si por el acto por el que se ha constituido la obligación, se estipuló dar moneda que no sea de curso legal en la República, la obligación debe considerarse como de dar cantidades de cosas y el deudor puede liberarse dando el equivalente en moneda de curso legal. 
Como se puede observar, la primera parte del citado artículo es obvia y, tanto el supuesto de hecho como su consecuencia, resultan plenamente válidos. Por ello es que no me voy a detener en este punto.

Lo que sí me llama la atención, es el contenido de la segunda parte, que establece que «si por el acto por el que se ha constituido la obligación, se estipuló dar moneda que no sea de curso legal en la República, la obligación debe considerarse como de dar cantidades de cosas y el deudor puede liberarse dando el equivalente en moneda de curso legal».

En principio, quiero poner énfasis en el hecho de que el numeral bajo análisis se encuentra contenido en el Parágrafo 6, «Obligaciones de dar dinero», de la Sección 1, «Obligaciones de dar», del Capítulo 3, «Clases de obligaciones», del Título I, «Obligaciones en general», del Libro Tercero, «Derechos personales», del Código Civil y Comercial.

En ese sentido, una primera interrogante es la relativa a por qué se mezclan conceptos y se incluyen supuestos y figuras normativas que no poseerían una relación directa, como es el caso de las obligaciones de valor (concepto distinto a las obligaciones de dar dinero, que se regula en el artículo 772).

Si nos encontramos ante un parágrafo, como el sexto, que regula expresamente las obligaciones de dar dinero, pues entonces, sólo este concepto debería encontrarse regulado en el parágrafo; y no otro.

Como señalaré más adelante, las obligaciones de dar monedas extranjeras, son obligaciones de dinero, y la nueva norma recurre al eufemismo y al error conceptual de considerarlas obligaciones de dar cosas distintas al dinero.

El supuesto normativo establece que si la obligación se constituye en moneda que no es de curso legal en el país, se «deberá» considerar la deuda como una de dar cantidades de cosas. Así, hubiera sido preferible, primero, señalar que dicha deuda se deba pagar en la moneda extranjera pactada. Total, si a las obligaciones de dar monedas extranjeras se les considera obligaciones de dar cantidades de cosas (distintas al dinero, ya que éste también es una cosa), pues entonces, lo lógico sería que se entreguen tales cosas dentro del artículo 766 del propio nuevo Código.

Lo mismo que ocurre si me obligo a dar mil naranjas, debería ocurrir cuando me obligue a dar mil dólares americanos. Aquí manda el principio de identidad.

Ésta debería ser siempre la primera opción, y la facultad de pago podría dejarse como se ha señalado, es decir, facultando al deudor para pagar esa prestación en moneda argentina.

Por otro lado, un aspecto importante a destacar es que la norma no aclara cómo es que se determinará el «equivalente en moneda de curso legal».

Y éste no es un tema menor, ya que tengo la impresión de que el contenido del precepto no otorga seguridad jurídica a las transacciones que reúnan los supuestos que regula esta norma. Digo ello, ya que no necesariamente existirá coincidencia entre la cotización oficial de la moneda extranjera con la moneda nacional, y el tipo de cambio o cotización comercial, de la misma. Esto generaría que se pueda terminar pagando un valor diminuto, expresado en pesos argentinos. 
Compartimos el parecer de Salerno, ${ }^{2}$ cuando señala que en casos en que el tipo de cambio oficial tenga una clara distorsión con el valor comercial de la moneda extranjera, adoptar una solución como ésta implicaría un riesgo de grave inequidad para el acreedor. Lo correcto en casos como éstos, es que el deudor deba — necesariamente- pagar en la especie pactada, es decir, en la moneda extranjera en la que se contrajo la obligación.

Dentro de tal orden de ideas, debo anotar que el artículo 765 del nuevo Código posee una serie de aspectos que bien podrían afinarse, en aras de otorgar mayor seguridad jurídica cuando nos encontremos ante obligaciones que deban pagarse en moneda distinta a la del curso oficial.

Por lo demás, sólo una reflexión final al respecto, y es la relativa a la naturaleza de las monedas extranjeras.

Vieja es la discusión en el sentido de si ellas son o no dinero.

Es evidente que dentro de una perspectiva absolutamente nacionalista, sólo será dinero del país la moneda de curso oficial; situación que no constituye obstáculo alguno para considerar que las monedas extranjeras también son dinero en sus respectivos países.

Por lo demás, las deudas contraídas en monedas extranjeras, no son deudas de valor, sino deudas dinerarias que deberán pagarse en el dinero del país en cuya moneda se ha contraído la obligación.

Prueba de ello es que cuando uno contrae una obligación en dólares americanos, o en cualquier moneda de país extranjero, no se está obligando a dar un valor, sino una cantidad de dinero de ese país.

El tema del valor sólo entra a tallar cuando la ley concede la facultad de pago en moneda local, como ocurre en la Argentina y en el Perú, en donde las obligaciones contraídas en moneda extranjera, son obligaciones de carácter facultativo, siendo la prestación principal el pago en la moneda extranjera pactada, y la prestación accesoria el pago en moneda peruana, en principio, al tipo de cambio del día del vencimiento de la obligación, regla que sufre algunas variaciones en caso el deudor incurra en mora.

Debo aclarar que entiendo la razón por la cual el tema se trata de esta manera en el nuevo Código argentino, habida cuenta de que aquí existe una política macroeconómica de control de cambios, y no un régimen de libre mercado en cuanto a las monedas extranjeras.

\section{3.- La cláusula penal (artículos 790 y siguientes del nuevo Código argentino)}

El nuevo Código Civil y Comercial argentino, ofrece la posibilidad de que los sujetos de la relación obligacional, en ejercicio de su autonomía privada, puedan establecer una cláusula penal en el contrato que celebren.

\footnotetext{
2 SALERNO, Marcelo. «Obligaciones dinerarias». En Análisis del proyecto de nuevo Código Civil y Comercial 2012. Buenos Aires. Facultad de Derecho de la Pontificia Universidad Católica Argentina \& El Derecho, 2012, p. 359.
} 
Como sabemos, la cláusula penal es la estipulación que se incluye en un contrato y se refiere a la pena o penalidad (cuantificada usualmente en términos monetarios), convenida para el caso en el que una de las partes incumpla alguna prestación.

No voy a referirme a aspectos gramaticales o accesorios del tema, sino a uno fundamental, cual es su mutabilidad o inmutabilidad.

El artículo 793 del nuevo Código estipula:

\section{Artículo 793.- Relación con la indemnización}

La pena o multa impuesta en la obligación suple la indemnización de los daños cuando el deudor se constituyó en mora; y el acreedor no tiene derecho a otra indemnización, aunque pruebe que la pena no es reparación suficiente.

Creemos que aquí se habría cometido un error y es que podría-verdaderamente- presentarse el caso en el cual los daños y perjuicios sean mucho mayores que el monto pactado como penalidad.

Como sabemos, la cláusula penal posee una función «formalmente» indemnizatoria, tanto cuando ella pudiera corresponder en su monto a la cuantía de los daños y perjuicios verdaderamente causados, como cuando resultare diminuta o excesiva. Y decimos «formalmente», pues sólo lo será en tanto indemnice daños y perjuicios causados. Cualquier exceso podrá tener carácter punitivo, mas no indemnizatorio.

Si la cláusula penal fuera diminuta, teniendo en cuenta la regulación que posee el nuevo Código, resulta evidente que el acreedor no podría demandar el aumento de la pena estipulada, y aquello que cobre, en este caso, sólo indemnizará parcialmente los daños y perjuicios causados. Ello es injusto, pues las penalidades se pactan a manera de sanción y disuasión del incumplimiento contractual, pero bien podría ocurrir que tales previsiones terminen siendo diminutas si se comparan con los daños sufridos.

Aquí hubiera sido conveniente establecer como excepción el caso del pacto de indemnización por daño ulterior. Otro tema que me parece interesante abordar es el relativo a la posibilidad de que los jueces disminuyan las penas. Dicha facultad se encuentra regulada en el artículo 794 del nuevo Código:

\section{Artículo 794.- Ejecución}

Para pedir la pena, el acreedor no está obligado a probar que ha sufrido perjuicios, ni el deudor puede eximirse de satisfacerla, acreditando que el acreedor no sufrió perjuicio alguno.

Los jueces pueden reducir las penas cuando su monto desproporcionado con la gravedad de la falta que sancionan, habida cuenta del valor de las prestaciones y demás circunstancias del caso, configuran un abusivo aprovechamiento de la situación del deudor. 
Aquí nos encontramos ante la posibilidad de modificar el monto de la penalidad, lo que conllevaría — en principioa desnaturalizar la institución bajo análisis, pues si el deudor puede solicitar su disminución cuando la considerase desproporcionada, dicha parte - y también el acreedor - tendrían que ingresar, necesariamente, a la probanza de los daños y perjuicios, lo cual importaría incurrir en lo que se quiso evitar mediante la estipulación de la cláusula penal.

Cabe señalar que este problema no se soluciona atribuyendo a quien solicite la modificación de la pena, la carga de probar que los daños infringidos sean mayores o menores que la penalidad pactada. En efecto, en los supuestos en que se solicite la reducción del monto de la pena, el deudor tendrá la carga de probar que los daños derivados de la inejecución son menores a la suma estipulada.

Sin embargo, un acreedor diligente, consciente de la posibilidad de que se reduzca el monto de la penalidad, entrará al tema probatorio, aun cuando esta carga no le sea impuesta por ley, a efectos de demostrar que los daños sufridos coinciden con el monto establecido en la cláusula penal, o que, incluso, son superiores a dicho monto.

No quiero que el auditorio piense que soy partidario de la inmutabilidad de la cláusula penal, porque en realidad no lo soy.

Si bien en mis obras siempre he respaldado la fuerza que debe tener dicha cláusula y las facilidades que deben existir para su cumplimiento, ello no implica que en la práctica toda penalidad deba pagarse tal cual haya sido convenida. Creo que los jueces sí deben tener, como de hecho también lo tienen dentro del ámbito del nuevo esquema argentino, la posibilidad de reducir las penalidades cuando la obligación ha sido parcialmente cumplida (artículo 798 del nuevo Código).

Es claro que en un caso como éste, si el deudor solicitara la reducción de la pena, y la porción de la prestación que se hubiese ejecutado revistiera utilidad para el acreedor, entonces, corresponderá reducir el monto de la penalidad.

Idéntico razonamiento podemos desarrollar cuando el cumplimiento de la obligación es defectuoso o irregular, pero a pesar de no tratarse de un cumplimiento idóneo, el mismo hubiera revestido beneficio para el acreedor.

En ambos casos, claro está, cabe que los tribunales, a solicitud de parte, reduzcan el monto de las penas, simplemente, porque de lo contrario se estaría consumando una injusticia.

El problema central se plantea cuando entramos al terreno de la subjetividad, que en el caso del nuevo Código argentino, se consagra con la extensa, alambicada y, a mi juicio, complicada expresión: «cuando su monto desproporcionado con la gravedad de la falta que sancionan, habida cuenta del valor de las prestaciones y demás circunstancias del caso, configuran un abusivo aprovechamiento de la situación del deudor».

Este problema en el Perú lo tenemos con el artículo 1346 del Código de 1984 y la posibilidad de reducir la pena a solicitud del deudor, «cuando ella sea manifiestamente excesiva». 
Creo que podemos coincidir en que, tanto la fórmula peruana como la argentina, otorgan importantes facultades a los jueces para reducir la penalidad, pero el artículo 794 del nuevo Código incluye la referencia a un abusivo aprovechamiento de la situación del deudor, lo que creo complica aún más las cosas.

En ese sentido, estimo que estas fórmulas de reducción de la penalidad a que acabo de hacer referencia, deberían ser analizadas dependiendo del carácter o naturaleza de la relación contractual en que se hubiese pactado la pena; ello, pues de no hacerlo, generalmente derivarán en que siempre se pueda reducir el monto de la misma.

En síntesis, creo que la reducción de las cláusulas penales podría prosperar en tanto y en cuanto nos encontremos frente a deudores que han celebrado contratos por adhesión o con cláusulas generales de contratación, pues en ellos será evidente que el deudor poco o nada habrá podido hacer para el establecimiento del monto de la penalidad.

Sin embargo, no pienso lo mismo cuando nos encontramos frente a contratos paritarios o de negociación previa, caso en el cual la reducción de la penalidad sólo debería proceder en los supuestos de cumplimiento parcial o defectuoso, a solicitud del deudor y con las características explicadas en su momento, pero no con la fórmula general, abierta y subjetiva de la última parte del artículo 794 del nuevo Código Civil.

Siempre he pensado en cuál sería la fórmula más justa para regular y aplicar en la práctica la cláusula penal; y ella no pasa, ni por su inmutabilidad absoluta, ni por la permanente posibilidad de reducir el monto pactado.

De igual modo, si hacemos una lectura conjunta de los numerales 793 y 794 del nuevo Código Civil y Comercial, podremos constatar que existe una evidente disparidad entre los derechos que se otorgan al deudor y los derechos que se otorgan al acreedor. Y ello es así ya que, por un lado, se permite que el monto de la cláusula penal pueda ser disminuido por los jueces si éste resulta desproporcionado, pero, contradictoriamente, no se permite que dicho monto pueda ser superior o, en todo caso, no se permite que se pueda reclamar a título indemnizatorio, otro monto distinto al establecido en la citada cláusula penal.

Así, pues, nos preguntamos si ello resulta justo; y creemos que la respuesta negativa se impone. En todo caso, reiteramos, lo idóneo hubiera sido que el legislador permita que se pueda estipular la indemnización de un daño ulterior como medida justa ante un supuesto en el que la cláusula penal resulte cuantitativamente menor al daño ocasionado por el incumplimiento.

\section{4.- Comentarios Finales}

Para concluir estas palabras, quiero señalar que reconozco muchas bondades en el nuevo Código Civil y Comercial argentino, comenzando por la propia unificación y la importancia que, de por sí, conlleva.

Analizar y referirme a ellas hubiera sido imposible, dada la naturaleza de mi exposición y la Jornada en la que se enmarca. 
Sólo nos queda esperar la maduración de este nuevo cuerpo normativo y que la doctrina y la jurisprudencia cumplan el papel que les corresponde, interpretando y logrando exponer sus verdaderos contenidos.

Un evento tan importante como las Jornadas Sanjuaninas, hace posible que el medio académico continúe debatiendo sobre los alcances del nuevo Código.

No olvidemos que la Argentina tiene un reto muy grande. Tratándose del país con la más rica doctrina civilista de América Latina, toda ella centrada en el Código de Vélez Sarsfield, tendrá ahora que asumir un cambio en su eje de rotación.

Hoy, cuando el objeto de estudio es otro, los países hermanos, que siempre hemos aprendido de la doctrina y del Derecho argentino, estamos ávidos de conocer todos los nuevos aportes y enseñanzas que recibiremos de ustedes. 